\title{
Current treatment options in vestibular migraine
}

\author{
Mark Obermann ${ }^{1}$ and Michael Strupp ${ }^{2}$ \\ 1 Department of Neurology, Vertigo and Dizziness Center, University of Duisburg-Essen, Essen, Germany \\ 2 Department of Neurology, German Center for Vertigo and Balance Disorder, Ludwig-Maximillians-University Munich, Munich, Germany
}

Edited by:

Stefan Evers, University of Muenster,

Germany

Reviewed by:

Paolo Rossi, Istituto

Neurotraumatologico Italiano (I.N.I.)

Grottaferrata, Italy

Elcio J. Piovesan, Universidade

Federal do Paraná, Brazil

\section{*Correspondence:}

Mark Obermann, Department of

Neurology, Vertigo and Dizziness

Center Essen, University of

Duisburg-Essen, Hufelandstr. 55,

Essen 45147, Germany

e-mail:mark.obermann@uni-due.de
Approximately $1 \%$ of the general population in western industrialized countries suffers from vestibular migraine. However, it remains widely unknown and often under diagnosed despite the recently published diagnostic criteria for vestibular migraine. Treatment trials that specialize on vestibular migraine are scarce and systematic randomized controlled clinical trials are now only emerging. This review summarizes the knowledge on the currently available treatment options that were tested specifically for vestibular migraine and gives an evidence-based, informed treatment recommendation with all its limitations. To date only two randomized controlled treatment trials provide limited evidence for the use of rizatriptan and zolmitriptan for the treatment of vestibular migraine attacks because of methodological shortcomings. There is an ongoing multicenter randomized placebocontrolled trial testing metoprolol $95 \mathrm{mg}$ vs. placebo (PROVEMIG-trial). Therefore, the therapeutic recommendations for the prophylactic treatment of vestibular migraine are currently widely based on the guidelines of migraine with and without aura as well as expert opinion.

Keywords: vestibular migraine, migraine with aura, migraine, vertigo, dizziness, gait disturbance

\section{INTRODUCTION}

Dizziness and headache are frequently reported symptoms in clinical neurology $(1,2)$. About $30-50 \%$ of all patients with migraine describe vertigo or dizziness associated with their migraine at least occasionally $(3,4)$. The International Headache Society (IHS), the Bárány-Society (International Society for Neuro-Otology), otorhinolaryngologists, and other scientists have created a consensus document with consistent diagnostic criteria for vestibular migraine $(5,6)$ that was considered in the appendix of the new ICHD-3 beta version of the international headache classification (7). These internationally accepted diagnostic criteria are intended to further promote the systematic research on vestibular migraine including clinical trials. Furthermore, they serve to create more certainty in diagnostic assessment and clinical management of these patients in everyday clinical practice. It remains an ongoing discussion whether vestibular migraine is an autonomous disorder with distinct pathophysiological features or whether it simply represents a subform of migraine that also includes vestibular symptoms (8).

Approximately two-thirds of the patients experience vertigo or dizziness seek professional medical care because of their symptoms, but only in $20 \%$ of all patients vestibular migraine was diagnosed (9). The various interpretations by different specialties regarding the combination of both symptoms, i.e., headache and vertigo, are alarming. A survey among neurologists and otologists reports that neurologists would diagnose a vestibular migraine in $82 \%$ of patients with vertigo and headache, while this opinion was shared only by $64.5 \%$ of ENT physicians. Surprisingly, in the context of this survey $19 \%$ of ENT physicians and even $14.5 \%$ of neurologists declared never to have treated a patient with vestibular migraine before (9).
Treatment trials that specifically address vestibular migraine are scarce and most treatment suggestions for vestibular migraine are extrapolated from knowledge gathered from clinical trials on migraine with and without aura. This review summarizes the current knowledge about treatment options that are specific for vestibular migraine.

\section{METHODS}

A Medline search was conducted to collect all available published data on the treatment of vestibular migraine. The search terms vestibular AND migraine returned 427 publications including 115 review articles and 18 labeled as clinical trial (October 2014). The combination of "vestibular migraine" returned 115 publications including two labeled as clinical trials and 37 as review articles. Overall, 22 publications were related to the specific treatment of vestibular migraine, not considering the numerous reviews about vestibular migraine and not considering the evidence rating. Some patients enrolled in these trials did not fulfill the later defined diagnostic criteria for vestibular migraine and in some, a different terminology was used. The most common terms to describe the combination of both (migraine and vestibular symptoms) besides vestibular migraine (10) were migrainous vertigo, migraine-associated vertigo, vertiginous migraine, migraineassociated balance disturbance, and benign paroxysmal vertigo.

\section{BURDEN OF VESTIBULAR MIGRAINE}

In population-based studies the lifetime prevalence of migraine and vertigo in the general population of Germany as a representative of the western industrial nations was approximately 16 and 7\%, respectively $(1,11)$. In the general population, the lifetime prevalence of vestibular migraine was $1 \%$, with a one-year 
prevalence of $0.9 \%$ (12). A large epidemiological study showed the concurrent presence of both symptoms in $3.2 \%$ of all patients (1). A different survey described the presence of dizziness or vertigo in $47.5 \%$ of patients with migraine during a severe migraine attack with pain intensity of 7 or more on a visual analog scale (VAS $0=$ no pain, $10=$ worst imaginable pain) (13).

Vestibular migraine can occur in any period of life $(10,14,15)$. Women are affected more frequently than men with a gender ratio between 1.5 and $5(10,15-17)$. A familial clustering as well as an autosomal-dominant inheritance with a lower penetrance in males was described (18). In most patients, vestibular migraine appears in an advanced period of life and often with a temporal delay to the first onset of migraine $(10,17)$. The association of vestibular symptoms with migraine with aura is controversial, as some studies found this connection $(10,17,19-22)$, while others discovered that patients with migraine without aura have vestibular symptoms more often or at least equally often as migraine with aura patients $(10,16,19)$. In elderly patients, especially in postmenopausal women, the typical migraine attacks are sometimes replaced by isolated episodes of vertigo, dizziness, or transient feeling of disequilibrium (23).

\section{CLINICAL PRESENTATION}

In a large population-based survey the most frequent vertigo symptoms were a spontaneous rotatory vertigo in $67 \%$ followed by positional vertigo in $24 \%$ of patients with vestibular migraine (12). Initial spontaneous rotatory vertigo can turn into a positional or illusion of movement type vertigo with gait disturbances $(24,25)$. An increased sensitivity to motion, particularly to movements of the head, or fast-moving visual objects are often part of the attack $(26,27)$.

The duration of attacks vary from few seconds $(10 \%$ of patients) to some minutes ( $30 \%$ of patients), some hours ( $30 \%$ of patients), and even up to a few days (30\% of patients) $(10,14$, $16,19)$. Only $10-30 \%$ of patients report a typical vestibular aura with duration between 5 and $60 \mathrm{~min}(10,17)$. Approximately $30 \%$ of all vestibular migraine attacks are not accompanied by headache $(14,16,17)$. In these cases, the typical migraine-associated symptoms like phono-/photophobia, osmophobia, nausea and vomiting, aggravation by movement, or the need to rest are the crucial symptoms for diagnosis (28). Gaze-induced nystagmus, saccadic pursuit (especially vertically), central positional nystagmus, and a slight horizontal or vertical spontaneous nystagmus can be observed during or after a migraine attack and might support the diagnosis (10).

\section{BASILAR-TYPE MIGRAINE}

Basilar-type migraine, in contrast to vestibular migraine, was already defined in the ICHD-2 classification and can be distinguished clearly from vestibular migraine in most cases (28). In the revised ICHD-3 beta classification, it is termed migraine with brainstem aura (7). Less than $10 \%$ of patients with vestibular migraine meet the diagnostic criteria for basilar-type migraine $(16,17)$. By definition, basilar-type migraine requires at least two aura symptoms, which are assignable to the vertebrobasilar territory, which last between 5 and $60 \mathrm{~min}$, and which are followed by a typical migraine headache (28). The extent to which both kinds of migraine can be distinguished and to what degree there are overlaps in some patients or disease constellations remains subject of current research.

\section{MEDICAL THERAPY}

There are two randomized controlled clinical studies on the specific treatment of vestibular migraine with triptans $(29,30)$. This study suggested a benefit from zolmitriptan $5 \mathrm{mg}$ in $38 \%$ (three of eight episodes) of patients with vestibular migraine attacks, whereas in the placebo group a positive effect was observed in only $22 \%$ (two of nine episodes). Unfortunately, the validity of this study is limited due to the large confidence intervals and the small number of patients recruited $(n=10)$ with only 17 reported attacks (29). A double-blind, randomized, placebocontrolled study with rizatriptan vs. placebo measured motion sickness in response to a complex vestibular stimulus. Subjects included 25 migraineurs with or without migraine-related dizziness ( 23 females) aged $21-45$ years ( $31.0 \pm 7.8$ years). Results indicated that of the 15 subjects who experienced vestibular-induced motion sickness 13 showed a decrease in motion sickness after rizatriptan compared to placebo $(p<0.02)$. However, this positive effect was not seen after exposure to more provocative vestibular stimulation. It was suggested by the authors that the serotonin agonist, rizatriptan, reduces vestibular-induced motion sickness by influencing serotonergic vestibular-autonomic projections (30).

All other therapeutic approaches are based on case reports, retrospective cohort studies, and open-label trials (Table 1). Many therapeutic recommendations for vestibular migraine are currently based on the guidelines of migraine with and without aura. This is supported by a large retrospective cohort evaluation on 100 patients (median age 47 years, range $21-72$ years) that compared vestibular migraine patients with and without prophylactic migraine treatment (31). All patients on prophylactic treatment showed a decrease of duration, intensity, and frequency of episodic vertigo as well as its associated features $(p<0.01)$. Medications used were beta-blocker [49 patients, metoprolol (69\%; median dose $150 \mathrm{mg}$ ) or propranolol (31\%; median dose $160 \mathrm{mg}$ )], valproic acid (6 patients, $8 \%$; median dose $600 \mathrm{mg}$ ), topiramate 6 patients (8\%; median dose $50 \mathrm{mg}$ ), butterbur extract 4 patients (5\%; median dose $50 \mathrm{mg}$ ), lamotrigine 3 patients (4\%; median dose $75 \mathrm{mg}$ ), amitriptyline (2 patients; 100 and $75 \mathrm{mg}$ ), flunarizine ( 1 patient: $5 \mathrm{mg}$ ), and magnesium (3 patients; median dose $400 \mathrm{mg}$ ). The group without prophylactic therapy showed a reduction of vertigo intensity only (31). A different retrospective study with 100 patients also indicated a positive effect of migraine prophylactic medication in patients with vestibular migraine (32). In the third retrospective cohort study, 33 patients with recurrent vertiginous attacks and migraine were evaluated. The assessment of frequency reduction showed complete disappearance in 19 patients $(57.6 \%)$, over $50 \%$ reduction in $8(24.2 \%)$, under $50 \%$ reduction in $5(15.2 \%)$, and no reduction in one patient. Propranolol was used by 12 patients, metoprolol by 2 , flunarizine by 7 , amitriptyline by 2 , and clonazepam by 11 patients (33).

Drugs intended for acute treatment such as sumatriptan, nonsteroidal anti-inflammatory drugs (NSAID), and ergots as well as preventive migraine medications such as beta blockers, tricyclic antidepressants, methysergide, flunarizine, topiramate, and 
Table 1 | Treatment options in vestibular migraine

\begin{tabular}{|c|c|c|}
\hline $\begin{array}{l}\text { Acute } \\
\text { treatment }\end{array}$ & Dosage & Trial (Reference) \\
\hline Zolmitriptan & $2.5 \mathrm{mg}$ oral & Randomized controlled trial (RCT) (29) \\
\hline Rizatriptan & $10 \mathrm{mg}$ oral & $\mathrm{RCT}$, motion sickness (30) \\
\hline \multicolumn{3}{|c|}{ PROPHYLACTICTREATMENT } \\
\hline \multirow[t]{2}{*}{ Metoprolol } & $150 \mathrm{mg}$ oral & Retrospective cohort analysis (31) \\
\hline & 100-200 mg oral & Retrospective cohort analysis (33) \\
\hline \multirow[t]{2}{*}{ Propranolol } & $160 \mathrm{mg}$ oral & Retrospective cohort analysis (31) \\
\hline & $40-160 \mathrm{mg}$ oral & Retrospective cohort analysis $(32,33)$ \\
\hline \multirow[t]{2}{*}{ Valproic acid } & $600 \mathrm{mg}$ oral & Retrospective cohort analysis (31) \\
\hline & $600 \mathrm{mg}$ oral & Cohort study, vestibulo-ocluar reflex (34 \\
\hline \multirow[t]{2}{*}{ Topiramate } & $50 \mathrm{mg}$ oral & Retrospective cohort analysis (31) \\
\hline & $50-100 \mathrm{mg}$ oral & Open-label, chart review (44) \\
\hline $\begin{array}{l}\text { Butterbur } \\
\text { extract }\end{array}$ & $50 \mathrm{mg}$ oral & Retrospective cohort analysis (31) \\
\hline \multirow[t]{2}{*}{ Lamotrigine } & $75 \mathrm{mg}$ oral & Retrospective cohort analysis (31) \\
\hline & $100 \mathrm{mg}$ oral & Retrospective, open-label (41) \\
\hline \multirow[t]{2}{*}{ Amitriptyline } & $100 \mathrm{mg}$ oral & Retrospective cohort analysis (31) \\
\hline & $10 \mathrm{mg}$ oral & Retrospective cohort analysis (33) \\
\hline Nortriptyline & $25-75 \mathrm{mg}$ oral & Open-label, chart review (44) \\
\hline \multirow[t]{3}{*}{ Flunarizine } & $5 \mathrm{mg}$ oral & Retrospective cohort analysis (31) \\
\hline & $5-10 \mathrm{mg}$ oral & Retrospective, open-label (33) \\
\hline & $5-10 \mathrm{mg}$ & Open-label, post-marketing $(36,37)$ \\
\hline Magnesium & $400 \mathrm{mg}$ oral & Retrospective cohort analysis (31) \\
\hline Clonazepam & $0,25-1 \mathrm{mg}$ oral & Retrospective cohort analysis (33) \\
\hline Cinnarizine & $37.5-75 \mathrm{mg}$ oral & Retrospective, open-label (35) \\
\hline \multicolumn{3}{|c|}{ NON-MEDICALTREATMENT } \\
\hline Vestibular & 5 therapy & Uncontrolled, observational trial (43) \\
\hline rehabilitation & sessions over & \\
\hline exercises & 9 weeks & \\
\hline $\begin{array}{l}\text { Caffeine } \\
\text { cessation }\end{array}$ & 4-6 weeks & Retrospective, observational trial (44) \\
\hline
\end{tabular}

valproate were studied (33). In a different study, sodium valproate did not relief vestibular symptoms but did have a considerable effect on migraine headache in 8 of 12 patients (34). In this study, the horizontal vestibulo-ocular reflex (VOR) was evaluated by sinusoidal harmonic acceleration test at 0.01, 0.02, 0.04, 0.08 , and $0.16 \mathrm{~Hz}$ using a computerized rotatory chair system. No abnormalities were found for the VOR gain, phase and asymmetry for any frequency. These normal VOR measurements contrasted with the repeated complaints of dizziness, vertigo and unsteadiness reported by seven patients $(58 \%)$ that remained unchanged by valproate treatment (34).

Cinnarizine was tested in a retrospective, single-center, openlabel, investigation of the effects of cinnarizine on vestibular migraine and migraine associated with vertigo (35). The study included 24 subjects with VM (23 women, 1 man) and 16 subjects with basilar type Migraine ( 12 women, 4 men). The ages of subjects ranged from 18 to 54 years (mean 30 years). The mean frequency of vertigo and also the mean frequency, duration and intensity of migraine headaches per month were reduced significantly after three months of cinnarizine therapy (all $p<0.001$ ) (35). This will have to be reconfirmed in a large scale, randomized, controlled clinical trial.

There are two large open-label post-marketing studies investigating flunarizine for the treatment of migraine and the treatment of vertigo $(36,37)$. In both conditions, flunarizine showed considerable efficacy compared to propranolol for migraine or betahistine for vertigo. Unfortunately, both studies did not look at patients that suffered from migraine and vertigo specifically and thus the effect of flunarizine can be suspected, but remains unproven. One randomized control trial (RCT) was undertaken in a tertiary academic center in order to evaluate the efficacy of flunarizine in 48 patients with vestibular migraine over 12 weeks in comparison to treatment with betahistine $16 \mathrm{mg}$ and vestibular exercises (38). The frequency of vertiginous episodes decreased with flunarizine treatment $(p=0.010)$ and severity of vertigo also improved $(p=0.046)$. Headache frequency and severity was not significantly different between treatment groups. The main side effects were weight gain and somnolence (38). A different retrospective chart study evaluated the effect of flunarizine and propranolol on vestibular migraine patients. Thirty patients with flunarizine showed a $68 \%$ responder rate of VM symptoms $(p<0.001)$. For propranolol, 31 patients showed an improvement of symptoms in $73 \%(p<0.001)(39)$.

Lamotrigine was reported to be effective in the treatment of migraine auras, isolated auras, and to a lesser extend migraineassociated headaches (40). One retrospective, open-label study investigated the efficacy of $100 \mathrm{mg}$ lamotrigine in 19 patients $(6$ men, 13 women) with vestibular migraine over 3-4 months. The average vertigo frequency per month was reduced from 18.1 to 5.4, headache frequency dropped from 8.7 to 4.4 , but did not reach statistical significance. Therefore, lamotrigine appears to mainly act on vestibular symptoms and only to a lesser extent on headaches (41). Lamotrigine was also effective in three patients with basilar-type migraine over five years (42).

Less conventional drugs such as benzodiazepines, selective serotonin reuptake inhibitors (SSRI), pizotifen, dothiepin, and acetazolamide, as well as behavioral modification such as special diets were reported to have a positive effect on vestibular migraine (33). However, it is difficult to extract a clear therapeutic recommendation for the particular treatment of vestibular migraine from these data. Furthermore, it must be kept in mind that inconsistent definitions of vestibular migraine were used in the context of these studies. As a result, the examined patient groups were quite heterogenous. In the future, this deficit should be eliminated by the new diagnostic criteria, hopefully leading to more comparable, high quality studies.

\section{NON-MEDICAL TREATMENT OPTIONS}

Vestibular rehabilitation exercises were described to be beneficial in patients with vestibular migraine in addition to medical treatment or as stand alone treatment option (43). Thirty-six patients (vestibular migraine $=20$, vestibular impairment $=16$ ) with daily vestibular symptoms received a 9 week vestibular rehabilitation program. Each subject attended five therapy appointments at initial, 2, 5, 9, and 6 months. While the vestibular migraine group 
showed poorer subjective performance at the onset of therapy, both groups benefited equally from rehabilitation. The same degree of improvement was observed in the migraine group regardless of medication regime. This study suggested that vestibular rehabilitation therapy may be effective in vestibular migraine regardless of the used medical prophylactic therapy (43). Even though, this is in line with the very positive effect of physical activity on the reduction of migraine with and without aura, yet again, a controlled study design is required in order to clearly recommend such a therapy approach.

\section{BEHAVIORAL MODIFICATION}

One interesting study investigated the cessation of caffeine for the treatment of vestibular migraine in 34 patients (44). Fourteen percent of patients reported improvement in symptoms upon caffeine cessation. In comparison, the same study showed that topiramate reduced symptoms in $25 \%$ of patients and $46 \%$ of patients reported a reduction in dizziness after nortriptyline therapy $(p=0.007)$. In total, $75 \%$ of VM patients received sufficient benefit from this therapeutic pathway to not progress to other treatments (44).

\section{RECOMMENDATIONS FOR TREATMENT}

The treatment recommendations for vestibular migraine are currently similar to those for migraine with or without aura because of the lack of specific trials in that field. Some of the following treatment recommendations are based on the authors' experience.

According to the available literature zolmitriptan $5 \mathrm{mg}$ (tablet, nasal spray, and dissolvable tablet) should be the first choice in the acute vestibular migraine attack. Rizatriptan may also be used and analogous to migraine any other triptan may be just as effective (45). Patients with excessive nausea or vomiting may prefer non-oral applications (i.e., nasal spray, suppositories or subcutaneous injections) or intravenous options such as acetylsalicylacid $1000 \mathrm{mg}$ where available with metoclopramide $10 \mathrm{mg}$ or dimenhydrinate $(62.5 \mathrm{mg})$. Prophylactic medications are not different from treatment of migraine with or without aura and include propranolol 80-240 mg, metoprolol 50-200 mg, bisoprolol 5-10 mg, or flunarizine $5-10 \mathrm{mg}$ per day in patients with over three attacks per month, with very long lasting or disabling attacks, or failure to respond to acute treatment. Topiramate $25-100 \mathrm{mg}$ and valproic acid 500-600 mg may be used as well. Combination of drugs belonging to the same class is probably not reasonable, and the combination of topiramate with propranolol did not show an additional benefit to topiramate alone (46). Patients with frequent migraine attacks on 15 days per month for $>3$ months and with $>8$ days with migraine headache per month for more than 3 months should receive topiramate $25-100 \mathrm{mg}$. A trial of onabotulinumtoxin type A (155 MU), as used in the treatment of chronic migraine, may also be reasonable, but this option is unlikely to improve vestibular symptoms. Patients who predominantly complain of vertigo or dizziness with typical aura duration, but without frequent migraine headache might be successfully treated with lamotrigine 25-100 mg per day (41).

\section{CONCLUSION}

So far there are no state-of-the-art published RCTs on the prophylactic treatment of vestibular migraine. There is, however, an ongoing multicenter randomized placebo-controlled trial (metoprolol $95 \mathrm{mg}$ per day vs. placebo; the PROVEMIG-trial). Established treatment regimens for migraine with and without aura can be effective in vestibular migraine, but it remains uncertain whether certain or more specific treatment options would be more beneficial for this special patient group. The knowledge derived from these clinical trials may also be useful for the distinction of vestibular migraine from migraine with and without aura, as well as from basilar-type migraine. Therefore, it could help to disentangle whether vestibular symptoms are merely one of the many migraine features or represent a genuine subform of migraine as suggested by current terminology of vestibular migraine.

\section{REFERENCES}

1. Neuhauser HK, von Brevern M, Radtke A, Lezius F, Feldmann M, Ziese T, et al. Epidemiology of vestibular vertigo: a neurotologic survey of the general population. Neurology (2005) 65(6):898-904. doi:10.1212/01.wnl.0000175987. $59991.3 \mathrm{~d}$

2. Rasmussen BK, Jensen R, Schroll M, Olesen J. Epidemiology of headache in a general population - a prevalence study. J Clin Epidemiol (1991) 44(11):1147-57. doi:10.1016/0895-4356(91)90147-2

3. Vukovic V, Plavec D, Galinovic I, Lovrencic-Huzjan A, Budisic M, Demarin V. Prevalence of vertigo, dizziness, and migrainous vertigo in patients with migraine. Headache (2007) 47(10):1427-35. doi:10.1111/j.1526-4610.2007. 00939.x

4. Cha YH, Lee H, Santell LS, Baloh RW. Association of benign recurrent vertigo and migraine in 208 patients. Cephalalgia (2009) 29(5):550-5. doi:10.1111/j. 1468-2982.2008.01770.x

5. Lempert T, Olesen J, Furman J, Waterston J, Seemungal B, Carey J, et al. Vestibuläre Migräne: diagnostische Kriterien, Konsensusdokument der BáránySociety und der International Headache Society. Nervenarzt (2013) 84(4):511-6. doi:10.1007/s00115-013-3768-x

6. Lempert T, Olesen J, Furman J, Waterston J, Seemungal B, Carey J, et al. Vestibular migraine: diagnostic criteria. J Vestib Res (2012) 22(4):167-72. doi:10.3233/VES-2012-0453

7. International Headache Society. The international classification of headache disorders, 3rd edition (beta version). Cephalalgia (2013) 33(9):629-808. doi:10. $1177 / 0333102413485658$

8. Stolte B, Holle D, Naegel S, Diener HC, Obermann M. Vestibular migraine. Cephalalgia (2014). doi:10.1177/0333102414535113

9. Millen SJ, Schnurr CM, Schnurr BB. Vestibular migraine: perspectives of otology versus neurology. Otol Neurotol (2011) 32(2):330-7. doi:10.1097/MAO. 0b013e3182040b21

10. Dieterich M, Brandt T. Episodic vertigo related to migraine (90 cases): vestibular migraine? J Neurol (1999) 246(10):883-92. doi:10.1007/s004150050478

11. Yoon MS, Katsarava Z, Obermann M, Fritsche G, Oezyurt M, Kaesewinkel $\mathrm{K}$, et al. Prevalence of primary headaches in Germany: results of the German Headache Consortium Study. J Headache Pain (2012) 13(3):215-23. doi:10.1007/s10194-012-0425-x

12. Neuhauser HK, Radtke A, von Brevern M, Feldmann M, Lezius F, Ziese T, et al. Migrainous vertigo: prevalence and impact on quality of life. Neurology (2006) 67(6):1028-33. doi:10.1212/01.wnl.0000237539.09942.06

13. Calhoun AH, Ford S, Pruitt AP, Fisher KG. The point prevalence of dizziness or vertigo in migraine - and factors that influence presentation. Headache (2011) 51(9):1388-92. doi:10.1111/j.1526-4610.2011.01970.x

14. Cutrer FM, Baloh RW. Migraine-associated dizziness. Headache (1992) 32(6):300-4. doi:10.1111/j.1526-4610.1992.hed3206300.x

15. Cass SP, Furman JM, Ankerstjerne K, Balaban C, Yetiser S, Aydogan B. Migraine-related vestibulopathy. Ann Otol Rhinol Laryngol (1997) 106(3):182-9. doi:10.1177/000348949710600302

16. Johnson GD. Medical management of migraine-related dizziness and vertigo. Laryngoscope (1998) 108(1 Pt 2):1-28. doi:10.1097/00005537-19980100100001

17. Neuhauser H, Leopold M, von Brevern M, Arnold G, Lempert T. The interrelations of migraine, vertigo, and migrainous vertigo. Neurology (2001) 56(4):436-41. doi:10.1212/WNL.56.4.436 
18. Oh AK, Lee H, Jen JC, Corona S, Jacobson KM, Baloh RW. Familial benign recurrent vertigo. Am J Med Genet (2001) 100(4):287-91. doi:10.1002/ ajmg. 1294

19. Kayan A, Hood JD. Neuro-otological manifestations of migraine. Brain (1984) 107(Pt 4):1123-42. doi:10.1093/brain/107.4.1123

20. Kuritzky A, Toglia UJ, Thomas D. Vestibular function in migraine. Headache (1981) 21(3):110-2. doi:10.1111/j.1526-4610.1981.hed2103110.x

21. Cha YH, Baloh RW. Migraine associated vertigo. J Clin Neurol (2007) 3(3):121-6. doi:10.3988/jen.2007.3.3.121

22. Akdal G, Ozge A, Ergor G. The prevalence of vestibular symptoms in migraine or tension-type headache. J Vestib Res (2013) 23(2):101-6. doi:10.3233/VES130477

23. Lempert T, Neuhauser H, Daroff RB. Vertigo as a symptom of migraine. Ann N Y Acad Sci (2009) 1164:242-51. doi:10.1111/j.1749-6632.2009.03852.x

24. Slater R. Benign recurrent vertigo. J Neurol Neurosurg Psychiatry (1979) 42(4):363-7. doi:10.1136/jnnp.42.4.363

25. Moretti G, Manzoni GC, Caffarra P, Parma M. "Benign recurrent vertigo" and its connection with migraine. Headache (1980) 20(6):344-6. doi:10.1111/j.15264610.1980.hed2006344.x

26. Waterston J. Chronic migrainous vertigo. J Clin Neurosci (2004) 11(4):384-8. doi:10.1016/j.jocn.2003.08.008

27. Drummond PD. Triggers of motion sickness in migraine sufferers. Headache (2005) 45(6):653-6. doi:10.1111/j.1526-4610.2005.05132.x

28. Headache Classification Subcommittee of the International Headache Society. The international classification of headache disorders: 2 nd edition. Cephalalgia (2004) 24(Suppl 1):9-160. doi:10.1111/j.1468-2982.2003.00824.x

29. Neuhauser H, Radtke A, von Brevern M, Lempert T. Zolmitriptan for treatment of migrainous vertigo: a pilot randomized placebo-controlled trial. Neurology (2003) 60(5):882-3. doi:10.1212/01.WNL.0000049476.40047.A3

30. Furman JM, Marcus DA, Balaban CD. Rizatriptan reduces vestibular-induced motion sickness in migraineurs. J Headache Pain (2011) 12(1):81-8. doi:10. 1007/s10194-010-0250-z

31. Baier B, Winkenwerder E, Dieterich M. "Vestibular migraine": effects of prophylactic therapy with various drugs. A retrospective study. J Neurol (2009) 256(3):436-42. doi:10.1007/s00415-009-0111-3

32. Bikhazi P, Jackson C, Ruckenstein MJ. Efficacy of antimigrainous therapy in the treatment of migraine-associated dizziness. Am J Otol (1997) 18(3):350-4.

33. Maione A. Migraine-related vertigo: diagnostic criteria and prophylactic treatment. Laryngoscope (2006) 116(10):1782-6. doi:10.1097/01.mlg.0000231302. 77922.c5

34. Gordon CR, Kuritzky A, Doweck I, Spitzer O, Shupak A, Hering R. Vestibuloocular reflex in migraine patients: the effect of sodium valproate. Headache (1993) 33(3):129-32. doi:10.1111/j.1526-4610.1993.hed3303129.x

35. Taghdiri F, Togha M, Razeghi Jahromi S, Refaeian F. Cinnarizine for the prophylaxis of migraine associated vertigo: a retrospective study. SpringerPlus. (2014) 3:231. doi:10.1186/2193-1801-3-231

36. de Bock GH, Eelhart J, van Marwijk HW, Tromp TP, Springer MP. A postmarketing study of flunarizine in migraine and vertigo. Pharm World Sci (1997) 19(6):269-74. doi:10.1023/A:1008617825269

37. Verspeelt J, De Locht P, Amery WK. Postmarketing study of the use of flunarizine in vestibular vertigo and in migraine. Eur J Clin Pharmacol (1996) 51(1):15-22. doi:10.1007/s002280050154
38. Lepcha A, Amalanathan S, Augustine AM, Tyagi AK, Balraj A. Flunarizine in the prophylaxis of migrainous vertigo: a randomized controlled trial. Eur Arch Otorhinolaryngol (2014) 271(11):2931-6. doi:10.1007/s00405-013-2786-4

39. Van Ombergen A, Van Rompaey V, Van de Heyning P, Wuyts F. Vestibular migraine in an otolaryngology clinic: prevalence, associated symptoms, and prophylactic medication effectiveness. Otol Neurotol (2014). doi:10.1097/MAO. 0000000000000596

40. Lampl C, Katsarava Z, Diener H-C, Limmroth V. Lamotrigine reduces migraine aura and migraine attacks in patients with migraine with aura. J Neurol Neurosurg Psychiatry (2005) 76(12):1730-2. doi:10.1136/jnnp.2005.063750

41. Bisdorff AR. Treatment of migraine related vertigo with lamotrigine an observational study. Bull Soc Sci Med Grand Duche Luxemb (2004) (2):103-8.

42. Cologno D, d'Onofrio F, Castriota O, Petretta V, Casucci G, Russo A, et al. Basilartype migraine patients responsive to lamotrigine: a 5-year follow-up. Neurol Sci (2013) 34(Suppl 1):S165-6. doi:10.1007/s10072-013-1384-y

43. Vitkovic J, Winoto A, Rance G, Dowell R, Paine M. Vestibular rehabilitation outcomes in patients with and without vestibular migraine. J Neurol (2013) 260(12):3039-48. doi:10.1007/s00415-013-7116-7

44. Mikulec AA, Faraji F, Kinsella LJ. Evaluation of the efficacy of caffeine cessation, nortriptyline, and topiramate therapy in vestibular migraine and complex dizziness of unknown etiology. Am J Otolaryngol (2012) 33(1):121-7. doi:10.1016/j.amjoto.2011.04.010

45. Ferrari MD, Roon KI, Lipton RB, Goadsby PJ. Oral triptans (serotonin 5$\mathrm{HT}(1 \mathrm{~B} / 1 \mathrm{D})$ agonists) in acute migraine treatment: a meta-analysis of 53 trials. Lancet (2001) 358(9294):1668-75. doi:10.1016/S0140-6736(01)06711-3

46. Silberstein SD, Dodick DW, Lindblad AS, Holroyd K, Harrington M, Mathew NT, et al. Randomized, placebo-controlled trial of propranolol added to topiramate in chronic migraine. Neurology (2012) 78(13):976-84. doi:10.1212/WNL. ob013e31824d5846

Conflict of Interest Statement: Mark Obermann has received scientific support and/or honoraria from Biogen Idec, Novartis, Sanofi-Aventis, Genzyme, Pfizer, Teva and Heel. He received research grants from Allergan, Electrocore, Heel and the German Ministry for Education and Research (BMBF). Michael Strupp is co-Chief Editor of the Journal of Neurology, and Specialty Chief Editor of Frontiers in Neurology - Neuro-otology and Section Editor of F1000. He has received speaker's honoraria from Abbott, Actelion, UCB, GSK, TEVA, Biogen Idec, Pierre-Fabre, Heel, Nordic, Eisai and Hennig Pharma and has received grants from the Federal Ministry of Education and Research (BMBF) and the Deutsche Forschungsgemeinschaft (DFG).

Received: 29 October 2014; accepted: 21 November 2014; published online: 04 December 2014.

Citation: Obermann M and Strupp M (2014) Current treatment options in vestibular migraine. Front. Neurol. 5:257. doi: 10.3389/fneur.2014.00257

This article was submitted to Headache Medicine and Facial Pain, a section of the journal Frontiers in Neurology.

Copyright (c) 2014 Obermann and Strupp. This is an open-access article distributed under the terms of the Creative Commons Attribution License (CC BY). The use, distribution or reproduction in other forums is permitted, provided the original author(s) or licensor are credited and that the original publication in this journal is cited, in accordance with accepted academic practice. No use, distribution or reproduction is permitted which does not comply with these terms. 